\title{
The global aspect of investing
}

\author{
Barbora Gabrikova, ${ }^{1, *}$ \\ ${ }^{1}$ University of Zilina, Faculty of Operation and Economics of Transport and Communications, \\ Univerzitna 1, 01026 Zilina, Slovakia
}

\begin{abstract}
Research background: Investing in the capital market is one of the ways for an investor to increase his income. Investing in the capital market is described as very risky, but it provides us with an opportunity to achieve high returns. There is an infinite number of assets on the market that an investor can include in his portfolio, and which assets he chooses to invest in will ultimately affect the return and risk of the created portfolio. Therefore, the investor should think rationally and should try to reduce the risk of his investment.

Purpose of the article: This article aims to point out the effect of diversification through the creation of a portfolio of financial assets.

Methods: This paper uses modern portfolio theory and focuses on the use of the Markowitz model. The optimal weights of individual assets in the compiled portfolio are calculated using the Lagrange function. We use data on weekly closing prices of individual stocks, commodity and mutual fund. Findings \& Value added: The main finding was that the risk associated with the created portfolio is lower than the risk associated with investing in individual assets.
\end{abstract}

Keywords: diversification; asset investment; modern portfolio theory; return; risk

JEL Classification: G10; G11; G15

\footnotetext{
${ }^{*}$ Corresponding author: barbora.gabrikova@stud.uniza.sk
} 


\section{Introduction}

In today's world, when globalisation is becoming popular not only in emerging economies (Yacob et al., 2020) but also in developed countries, one of its distinctive features is the growing economic integration between countries, especially in the areas of production, investment, commercialisation, and finance. Globalisation in financial markets is associated with creating sophisticated financial products traded on various capital markets (Nasreen et al., 2020; Galo and Byron, 2018). Moreover, financial globalisation has opened international capital markets to investors and companies worldwide (Paskaleva and Stoykova, 2021).

An investor can currently invest his capital in a wide range of assets. He can choose between stocks, bonds, commodities, mutual funds, real estate, cryptocurrencies and others to ensure the growth of assets (Grofcikova, 2020).

Participants face different types of risks when investing in financial markets. Investments are often risky due to unpredictable events in the future. Most investors aim to reduce the overall risk that arises from a given investment. One of the ways how investors can reduce overall risk is diversification (Xu and Shiina, 2018). Portfolio diversification generally consists of distributing wealth among different assets, investors invest their funds in many assets. Its advantage is the reduction of risk minimising the probability and severity of portfolio loss through multilateral insurance, in which each asset is insured with the remaining assets (Koumou, 2020; Jayeola et al., 2017).

In order to diversify their portfolios and increase growth opportunities, more and more investors are choosing to allocate their funds to foreign equities and derivatives (Zhang et al., 2018).

The basics of modern portfolio theory were laid by Harry Markowitz in his work "Portfolio Selection," first published in The Journal of Finance in 1952. Until then, assets had been selected for the portfolio solely based on profitability. Thus, the investor chose the ones that had the highest return regardless of the risk. Markowitz's modern portfolio theory focuses primarily on portfolio risk. Under this approach, an investor can reduce the risk associated with his portfolio simply by including asset combinations in his portfolio that are not highly positively correlated (Markowitz, 1952; Aksaryli and Pala, 2018).

Jayeola et al. (2017) examined the effects of assets such as gold, silver, platinum and oil on portfolio risk optimisation. And they found that among the assets mentioned above, diversification in gold minimises higher risk and acts as a hedge in times of economic crisis.

Given the increase in cryptomen trade volumes, Liu (2019) analysed the role of diversification in the cryptomen market in his recent study. He pointed out that portfolio diversification between different cryptocurrencies can significantly improve investment results. The impact of cryptocurrency - Bitcoin on portfolio diversification is discussed in more depth by, for example, Akhtaruzzaman et al. (2020).

In a recent study, Khan et al. (2020) tried to create an optimal portfolio including indicators of higher order, skewness, and sharpness. The results show that the optimal portfolios, including skewness and sharpness indicators, are sustainable and significantly different from the optimal portfolios deviating to the mean deviation.

This article aims to point out the effect of diversification by creating a portfolio of financial assets. The structure of the article is as follows. In the introduction section, we deal with the theoretical basis and highlight the current state of the research of the issue. Then, in the methods section, we deal with the use of methods of modern portfolio theory, where we compile a portfolio with minimal risk based on available data from the website www.finance.yahoo.com. Finally, in the results section, we present a compiled portfolio in which we calculated the weights of individual assets using the Lagrange function. The most important findings are listed in the discussion section. 


\section{Methods}

The investor has several investment strategies available when creating a portfolio. An investor may create portfolios with different characteristics, may create a portfolio with naive diversification, a portfolio with minimal risk, a portfolio with minimum risk and a predetermined return, a portfolio with minimum risk in which short selling will be prohibited or may create a portfolio with the possibility of investing in a risk-free asset.

In this article, we decided to create a portfolio with minimal risk. The Minimum risk portfolio has a minimum standard deviation of returns (Thirimanna et al., 2013; Siekelova et al., 2021).

When creating a portfolio with minimal risk, it is necessary to minimise the purpose variance function, which is given by the following formula

$$
\sigma_{P}^{2}=\sum_{i=1}^{n} \sum_{j=1}^{n} x_{i} x_{j} \sigma_{i j} \rightarrow M I N
$$

where $x_{i}$ is the weight of the $\mathrm{i}$-th asset in the portfolio, $x_{j}$ is the weight of the $\mathrm{j}$-asset in the portfolio, $\sigma_{i j}$ is a covariance of the $\mathrm{i}$-th and $\mathrm{j}$-th investment assets and $n$ is a number of assets in the portfolio.

In addition to minimising the purpose function, however, it is necessary to observe the condition that the sum of weights is equal to one. For calculation of the weights of individual assets in the portfolio, the Lagrange function may be used. It has the following form:

$$
L\left(x_{1}, x_{2}, \ldots, x_{n}, \lambda\right)=\sum_{i=1}^{n} \sum_{j=1}^{n} x_{i} x_{j} \sigma_{i j}+\lambda\left(\sum_{i=1}^{n} x_{i}-1\right)
$$

It is necessary to create a system of partial derivatives of this function according to individual variables $x_{1}, x_{2}, \ldots, x_{n}$ and $\lambda$. Where $\lambda$ represents the Lagrange multiplier that falls under the constraint on the sum of the weights and the variables $x_{1}, x_{2}, \ldots, x_{n}$ represent the weights of the individual assets in the portfolio. The bound local extrema will then be located at a point where the partial derivatives are zero.

When compiling a portfolio with minimal risk, we decided to compile a portfolio of stocks, commodity, and mutual fund. When selecting specific assets for the portfolio, the decisive condition was that the individual assets had a negative or as low a positive correlation coefficient as possible (Svabova et al., 2020), and also that the stocks of individual companies were from different sectors such as industrials, technology, communication services, consumer defensive and others.

We created the portfolio from assets traded on the New York Stock Exchange, Nasdaq, and the New York Board of Trade. The data on which we relied are available on the website www.finance.yahoo.com. We used the weekly closing prices (in USD) of individual financial assets over a period of three years (22.01.2018 - 31.01.2021). The composition of the portfolio is shown in Table 1.

Table 1. The composition of the portfolio

\begin{tabular}{|l|c|}
\hline \multicolumn{1}{|c|}{ The name of the investment asset } & type of investment assets \\
\cline { 1 - 1 } AP - Ampco-Pittsburgh Corporation & \\
\cline { 1 - 1 } CMCL - Caledonia Mining Corporation & \multirow{2}{*}{ stocks } \\
\cline { 1 - 1 } CTG - Computer Task Group, Incorporated & \\
\hline
\end{tabular}




\begin{tabular}{|c|c|}
\hline \multirow{2}{*}{$\begin{array}{l}\text { DIT- AMCON Distributing company } \\
\text { JCTCF - Jewett-Cameron Trading Company }\end{array}$} & \\
\hline & \\
\hline NL - NL Industries, Inc. & \\
\hline TNK - Teekay Tankers Ltd. & \\
\hline USM - United States Cellular Corporation & \\
\hline VYGR - Voyager Therapeutics, Inc. & \\
\hline WMK - Weis Markets, Inc. & \\
\hline Cotton & commodity \\
\hline VBLLX & mutual fund \\
\hline
\end{tabular}

Source: own processing according to www.finance.yahoo.com (2021)

\section{Results}

To be able to use the Lagrange function to calculate the optimal weights of individual assets in a portfolio, it is necessary to quantify the return and risk as volatility of returns (Bin et al., 2020) of stocks, commodity and the mutual fund from the weekly closing prices of individual assets. The summary results of returns and risks are shown in Table 2.

Table 2. Return and risk of financial assets

\begin{tabular}{|l|c|c|}
\cline { 2 - 3 } \multicolumn{1}{c|}{} & return [\%] & risk [\%] \\
\hline AP & -0.532 & 9.516 \\
\hline CMCL & 0.479 & 8.587 \\
\hline CTG & 0.133 & 6.922 \\
\hline DIT & 0.194 & 6.119 \\
\hline JCTCF & 0.132 & 5.446 \\
\hline NL & -0.693 & 9.268 \\
\hline TNK & -0.003 & 9.176 \\
\hline USM & -0.078 & 5.681 \\
\hline VYGR & -0.677 & 9.746 \\
\hline WMK & 0.160 & 3.698 \\
\hline Cotton & 0.001 & 3.123 \\
\hline VBLLX & 0.152 & 1.747 \\
\hline
\end{tabular}

Source: own processing (2021)

From table 2, we can see that the stocks of USM, TNK, NL, AP, and VYGR achieve a negative return, and most of these stocks have more than $9 \%$ risk. The riskiest is stock VYGR, the less risky is mutual fund VBLLX.

After calculating the returns and risks of individual assets, we can calculate the optimal weights of individual assets in the portfolio using the Lagrange function.

Table 3. Weights of assets in the portfolio

\begin{tabular}{|l|l|}
\hline AP & -0.0088 \\
\hline
\end{tabular}




\begin{tabular}{|l|c|} 
CMCL & -0.0377 \\
\hline CTG & -0.0388 \\
\hline DIT & 0.0559 \\
\hline JCTCF & 0.0101 \\
\hline NL & -0.0003 \\
\hline TNK & 0.0304 \\
\hline USM & 0.0586 \\
\hline VYGR & -0.0150 \\
\hline WMK & 0.0991 \\
\hline Cotton & 0.1942 \\
\hline VBLLX & 0.6523 \\
\hline
\end{tabular}

Source: own processing (2021)

A negative weight value signals a short sale. A short sale is often referred to as an investment strategy in which the investor speculates that the prices of individual investment assets will fall (Gerazi et al., 2018). After determining the weights of assets in the portfolio, we can quantify the value of return $\left(\overline{R_{P}}\right)$ and risk $\left(\sigma_{P}\right)$ of the total portfolio.

$$
\begin{gathered}
\overline{R_{P}}=0,001146934 \cdot 100 \%=0,1147 \% \\
\sigma_{p}^{2}=0,000131945 \\
\sigma_{P}=\sqrt{0,000131945}=0,011486732 \cdot 100 \%=1,1487 \%
\end{gathered}
$$

For better clarity, we can show the resulting values of returns and risks of the portfolio as well as the individual assets that make up it in the area of risk and return.

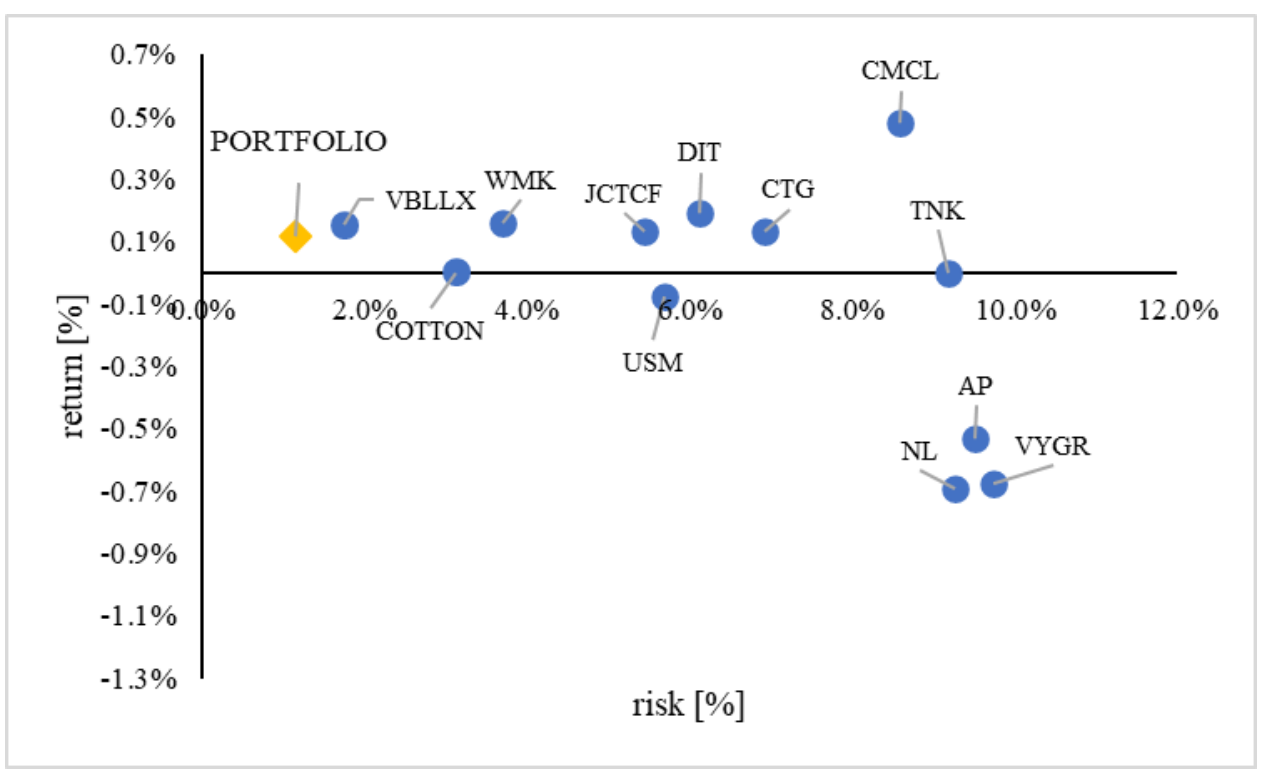

Figure 1. Portfolio with minimal risk in the area of risk and return

Source: own processing (2021)

Figure 1 shows the effect of diversification. It shows that the portfolio risk is the smallest compared to the risk associated with individual assets. The relative return of this portfolio is not the highest of the returns on individual assets. However, a portfolio constructed in this 
way in terms of the degree of risk and return is appropriate if the investor is characterised by risk aversion.

\section{Discussions and Conclusions}

From the available investment instruments, the investor can compile an infinite number of portfolios. Using the Lagrange function, the investor can compile portfolios that meet predetermined criteria, such as minimum risk, a set level of return, or a short-selling restriction. Modern portfolio theory provides the investor with the opportunity to compile portfolios that will be effective for him.

The weakness of this study may be the fact that we focused on assets that are traded on the New York Stock Exchange, Nasdaq and the New York Board of Trade. To better illustrate the effect of diversification, an investor could try to compile his portfolio from different investment instruments located on the capital markets in different countries, which would allow him to insure in some way against various economic or political shocks that have negative effects on development on the capital markets.

Modern portfolio theory is based on various assumptions, such as the absence of taxes or transaction costs, the existence of rational investors who are looking for a portfolio that would be fully diversified presupposes a perfectly liquid market and others (Pruchnicka-Grabias, 2013). These assumptions are normally unsatisfiable. If there were no presumption that we abstract from taxes when compiling portfolios, it would mean that the investor would be forced to follow the tax policies of specific countries in which capital markets he wants to invest. The total amount of the tax burden on his future income would thus become an important criterion for his decision. The existence of transaction costs, in turn, would mean that if the investor deducted all the costs associated with the transaction from the return he had made, he could make a loss from the initially positive return.

Covid-19 affected more sectors like transport (Poliak et al., 2021), tourism, electronics, and spa industry (Stefko et al., 2020), but capital markets were also affected in this case.

\section{References}

1. Akhtaruzzaman, M., Sensoy, A., \& Corbet, S. (2020). The influence of bitcoin on portfolio diversification and design. Finance Research Letters, 37, Article 101344.

2. Aksarayl1, M., \& Pala, O. (2018). A polynomial goal programming model for portfolio optimisation based on entropy and higher moments. Expert Systems with Applications, 94, 185-192.

3. Bin, L., Chen, J., \& Ngo, A. X. (2020). Revisiting executive pay, firm performance, and corporate governance in China. Economics, Management and Financial Markets, 15(1), 9-32.

4. Galo, A. P., \& Byron, A. L. (2018). Influence of financial globalisation in the ecuadorian stock market. Ciencia unemi, 11(27), 52-65.

5. Geraci, M. V., Garbaravicius, T., \& Veredas, D. (2018). Short selling in extreme events. Journal of Financial Stability, 39, 90-103.

6. Grofcikova, J. (2020). Impact of selected determinants of corporate governance on financial performance of companies. Economic and Managerial Spectrum, 14(2), 12 24.

7. Jayeola, D., Ismail, Z., \& Sufahani, S. F. (2017). Effects of diversification of assets in optimising risk of the portfolio. Malaysian Journal of Fundamental and Applied Science, 13(4), 584-587. 
8. Khan, K. I., Naqvi, S. M., Ghafoor, M. M., \& Akash, R. S. I. (2020). Sustainable Portfolio Optimization with Higher-Order Moments of Risk. Sustainability, 12(5), Article 2006.

9. Koumou, G. B. (2020). Diversification and portfolio theory: a review. Financial Markets and Portfolio Management, 34(3), 267-312.

10. Liu, W. (2019). Portfolio diversification across cryptocurrencies. Finance Research Letters, 29, 200-205.

11. Markowitz, H. (1952). Portfolio selection. Journal of Finance, 7(1), 77-91.

12. Nasreen, S., Mahalik, M. K., Shahbaz, M., \& Abbas, Q. (2020). How do financial globalisation, institutions and economic growth impact financial sector development in European countries?. Research in International Business and Finance, 54, Article 101247.

13. Paskaleva, M., Stoykova, A. (2021). Globalisation effects on contagion risks in financial markets, Ekonomicko-manazerske spektrum, 15(1), 38-54.

14. Poliak, M., Svabova, L., Konecny, V., Zhuravleva, N. A., \& Culik, K. (2021). New paradigms of quantification of economic efficiency in the transport sector . Oeconomia Copernicana, 12(1), 193-212.

15. Pruchnicka-Grabias, I. (2013). Risk Underestimation As A Consequence Of Assumptions Made In Valuation Models. Journal of Finance, 19, 425-442.

16. Siekelova, A., Belas, J., Podhorska, I., Durana, P. (2021). Accrual-Based Earnings Management: A Case Study in V4 Focusing on Mining And Quarrying Sector. Acta Montanastica, Slovaca, 26(1), 70-83.

17. Stefko, R., Jencová, S., \& Vasanicová, P. (2020). The Slovak Spa Industry and Spa Companies: Financial and Economic Situation. Journal of Tourism and Services, 20 (11), 28-43.

18. Svabova, L., Valaskova, K., Durana, P., \& Kliestik, T. (2020). Dependency analysis between various profit measures and corporate total assets for Visegrad group's business entities. Organizacija, 53(1), 80-90.

19. Thirimanna, T. H. S. R., Tilakartane, C., Mahakalanda, I., \& Pathirathne, L. (2013). Portfolio selection using cointegration and modern portfolio theory: An application to the Colombo Stock Exchange. MATEMATIKA: Malaysian Journal of Industrial and Applied Mathematics, 29(1), 195-202.

20. Virglerova, Z., Conte, F., Amoah, J., \& Massaro, M. R. (2020). The Perception of Legal Risk and Its Impact on the Business of SMEs. International Journal of Entrepreneurial Knowledge, 8(2), 1-13.

21. Xu, C., \& Shiina, T. (2018). Financial Investment, Financial Risk and Risk Management. Risk Management in Finance and Logistics (pp. 3-11). Springer.

22. Yacob, N., Mustapha, M., Abdullah, S. M. M., \& Ya'acob, F. F. (2020). Incorporating investor behaviour in portfolio management in developed and emerging OECD stock markets. Polish Journal of Management Studies, 22(1), 611-625.

23. Zhang, Y., Gao, J., \& An, Q. (2018). International investing in uncertain financial market. Soft Computing, 22(16), 5335-5346. 